\title{
Cinética ruminal da fração fibrosa de volumosos para ruminantes ${ }^{1}$
}

\author{
Ruminal kinetics of the fibrous fraction of ruminant roughages
}

\author{
Elaine Barbosa Muniz ${ }^{2}$, Ivone Yurika Mizubuti ${ }^{3}$ Elzânia Sales Pereira ${ }^{4 *}$, Patrícia Guimarães Pimentel ${ }^{4}$, Edson \\ Luiz de Azambuja Ribeiro ${ }^{3}$ e Andréa Pereira Pinto ${ }^{4}$
}

\begin{abstract}
RESUMO - Os objetivos do presente trabalho foram a caracterização e a determinação das estimativas dos parâmetros relativos à cinética de degradação ruminal da fibra em detergente neutro (FDN) dos fenos de mata pasto, juazeiro, mororó, aveia e Tifton 85 e silagens de milho, sorgo e palma forrageira. Foram determinados a composição químico-bromatólogica, os coeficientes de degradação e o efeito de repleção ruminal da FDN. As características químico-bromatológicas dos alimentos avaliados apresentaram variações em seus componentes nutricionais. A fração insolúvel potencialmente degradável da FDN, correspondente à fração B2 dos alimentos estudados, apresentou degradação variável. Os fenos de mata pasto, juazeiro e mororó apresentaram menores valores para a fração potencialmente degradável. As silagens de milho e sorgo apresentaram uma pequena variação para a fração potencialmente degradável e para a fração indigestível, assim como, para a taxa de degradação da FDN potencialmente digestível. O maior tempo de retenção total foi observado para mata pasto, juazeiro e mororó, seguidos pelas silagens, sendo constatados para os fenos de aveia e Tifton 85 os menores valores para esta variável. As forrageiras de regiões semiáridas avaliadas (mata pasto, juazeiro e mororó) podem limitar o consumo de matéria seca devido aos menores valores da fração potencialmente degradável e maiores valores da fração indigestível. O efeito de repleção ruminal da FDN é determinado pela integração de várias características da fibra. Dessa maneira, não se pode atribuir a toda e qualquer fonte de fibra as mesmas inferências restritivas à limitação física de consumo.
\end{abstract}

Palavras-chave: Alimentos. Composição dos alimentos. Rações para ruminante.

\begin{abstract}
The objectives of the present work were to characterize and determine the estimates of the parameters relating to the kinetics of ruminal degradation of neutral detergent fiber (NDF) in hays from forest pasture, the jujube plant, mororo, oats and Tifton 85, and silages from corn, sorghum and forage cactus. The bromatologic-chemical composition, the degradation coefficients and the effect of ruminal fill of the NDF, were all determined. The bromatologic-chemical characteristics of the feeds under evaluation displayed variations in their nutritional components. The potentially degradable insoluble fraction of the NDF, corresponding to the B2 fraction of the studied feeds, showed variable deterioration. Hays from forest pasture, the jujube plant and mororo showed lower values for the potentially degradable fraction. The silages from corn and sorghum showed a small variation in the potentially degradable fraction and in the indigestible fraction, as well as in the degradation rate of the potentially digestible NDF. The highest total retention time was observed for forest pasture, the jujube plant and mororo followed by the silages, with the lowest values for this variable found in the hays from oats and Tifton 85. Forages, evaluated from semiarid regions (forest pasture, jujube and mororo), may limit dry-matter intake due to lower values of the potentially degradable fraction and higher values of the indigestible fraction. The effect of NDF ruminal fill is determined by the integration of various fiber characteristics. Thus the same restrictive inferences on physical intake cannot be made for any and all sources of fiber.
\end{abstract}

Key words: Feeds. Feeds composition. Rations for ruminants.

\footnotetext{
*Autor para correspondência

${ }^{1}$ Recebido para publicação em 25/10/2010; aprovado em 06/02/2012

Parte da Tese de Doutorado da primeira autora apresentada no Departamento de Zootecnia-UEL/Londrina-PR, Brasil

${ }^{2}$ Programa de Pós-Graduação em Ciência Animal/UEL, Londrina-PR, Brasil, ebmuniz@ homail.com

${ }_{3}^{3}$ Departamento de Zootecnia/UEL, Pesquisadores do CNPq, Londrina-PR, Brasil, mizubuti@uel.br, elar@uel.br

${ }^{4}$ Departamento de Zootecnia/UFC/Pesquisadores do CNPq, Fortaleza-CE, Brasil, elzania@hotmail.com, pgpimentel@ hotmail.com, deiapp@ hotmail.com
} 


\section{INTRODUÇÃO}

A obtenção de estimativas de digestibilidade é essencial para se conhecer o valor energético dos alimentos, notadamente via nutrientes digestíveis totais, o que permite o balanceamento adequado de rações que propiciem o atendimento das demandas para mantença e produção dos animais. Entre os diferentes componentes dos alimentos, a fração fibrosa é de fundamental importância em sistemas de produção tropical, pois fornece quantidade significativa de energia a baixo custo, e apresenta variabilidade naturalmente superior aos demais componentes, devendo ocupar posição central na avaliação da disponibilidade de energia (DETMANN et al., 2004). A obtenção da contribuição energética dos diferentes componentes a partir de seus teores nos diferentes alimentos tem sido sugerida por diversos autores (CABRAL et al., 2000, 2005; DETMANN et al., 2007; VAN SOEST, 1994). Essa proposição visa contornar o ônus de recursos financeiros e de tempo dos tradicionais ensaios de digestão in vivo.

A avaliação de forrageiras tem grande valor prático na alimentação de ruminantes. Como primeiro passo para essa avaliação, foram inicialmente propostos sistemas que propiciam a obtenção de estimativas da digestibilidade. Vários métodos têm sido desenvolvidos com este propósito, entre eles, o obtido por mensurações gravimétricas que utilizam tempo único de incubação, como o método da digestibilidade in vitro, proposto na década de 60. Contudo, para que se obtenham estimativas mais acuradas dos parâmetros digestivos dos alimentos, é necessário obter estimativas das taxas de degradação ruminal destes alimentos. De forma alternativa aos métodos biológicos, a utilização da composição química dos alimentos, como método de predição da digestão em ruminantes, tem sido sugerida por diversos autores (NATIONAL RESEARCH COUNCIL, 2001; ROCHA JÚNIOR et al., 2003; VAN SOEST, 1994). Como ponto inicial aos principais métodos, destaca-se a estimação do potencial de degradação da fibra em detergente neutro (FDN), expresso complementarmente como sua fração indigestível, ou FDNi. Esta porção é empregada como base para estimação da digestão efetiva dos componentes fibrosos, sendo, no entanto, seu estudo isolado preponderante ao entendimento dos efeitos de repleção física ao ambiente ruminal. Por ser indigestível e agir na redução da fração fibrosa potencialmente digestível da parede celular (CASSIDA et al., 2007), a lignina é geralmente aceita como a entidade primária responsável pela limitação da digestão das forragens (VAN SOEST, 1994), sendo adotada como base para a estimação do teor de FDNi por dois dos principais sistemas nutricionais da atualidade: o Cornell Net Carbohydrate and Protein System (CNCPS) e o National Research Council (NRC). No entanto, embora hajam recentes propostas de avaliação das equações estabelecidas por estes sistemas, em condições nacionais (PEREIRA et al., 2001; ROCHA JÚNIOR et al., 2003; VIEIRA et al., 2000), pouco se conhece acerca do potencial preditivo de tais equações para gramíneas produzidas em regiões tropicais.

Diante disso, os objetivos do presente trabalho foram a caracterização e a determinação das estimativas dos parâmetros relativos à cinética de degradação ruminal da fibra em detergente neutro (FDN) dos fenos de mata pasto (Senna obtusifolia L.), juazeiro (Ziziphus joazeiro Mart.), mororó (Bauhinia cheilanta), aveia (Avena sativa L.) e Tifton 85 (Cynodon dactylon), e das silagens de milho (Zea mays L.), sorgo (Sorghum bicolor L.) e palma (Opuntia fícus - Indica).

\section{MATERIAL E MÉTODOS}

O experimento foi conduzido nas dependências do Laboratório de Nutrição Animal, do Departamento de Zootecnia da Universidade Federal do Ceará, Fortaleza, Ceará. Os volumosos avaliados foram os fenos de mata pasto (Senna obtusifolia L.), juazeiro (Ziziphus joazeiro Mart.), mororó (Bauhinia cheilanta), aveia (Avena sativa L.) e Tifton 85 (Cynodon dactylon), e as silagens de milho (Zea mays L.), sorgo (Sorghum bicolor L.) e palma forrageira cv. gigante (Opuntia fícus - Indica).

Inicialmente, as amostras das silagens foram présecas em estufa de ventilação forçada a $55^{\circ} \mathrm{C}$ por 72 horas. Em seguida, todos os alimentos foram triturados em moinho estacionário "Thomas Wiley", utilizando-se peneira com malha de 1,0 mm de crivo. Posteriormente, procedeu-se a quantificação de matéria seca (MS), matéria mineral (MM), proteína bruta $(\mathrm{PB})$ e extrato etéreo (EE), conforme os procedimentos recomendados por Silva e Queiroz (2002). As análises de fibra em detergente neutro (FDN) e ácido (FDA) foram realizadas segundo Van Soest, Robertson e Lewis (1991) e lignina (ácido sulfúrico 72\%) obtida pelo método sequencial de Van Soest e Robertson (1980).

Para as incubações in situ para a estimação dos parâmetros cinéticos de degradação da FDN, as amostras foram moídas em peneira de $5 \mathrm{~mm}$ de crivo e foram incubadas em sacos de náilon com $50 \mu \mathrm{m}$ de abertura entre malha, medindo $6 \times 14 \mathrm{~cm}$. Os tempos de incubação foram: $0 ; 6 ; 16 ; 48 ; 96$ e 144 horas, utilizando-se para tal um animal Pardo-Suíço fistulado no rúmen, o qual foi mantido em regime de semi-confinamento recebendo ração à vontade, com relação de volumoso:concentrado de 70:30. O procedimento de incubação foi repetido cinco vezes, perfazendo o total de cinco avaliações por tempo de incubação para cada alimento. Ao final de cada tempo de incubação, os sacos foram retirados do rúmen, sendo então lavados em água corrente, até que se apresentassem limpos e, posteriormente, secos em estufa com ventilação forçada 
a $55{ }^{\circ} \mathrm{C}$ durante $72 \mathrm{~h}$, sendo posteriormente colocados em dessecador e pesados. Os sacos correspondentes ao tempo zero hora (fração prontamente solúvel) foram submetidos aos mesmos procedimentos destinados aos demais tempos de incubação. Posteriormente, os sacos foram submetidos à fervura em detergente neutro por uma hora, sendo lavados em seguida com água quente até a eliminação do excesso de detergente e submetidos a uma lavagem com acetona. Em seguida, secos em estufa com ventilação forçada por 72 horas e pesados para obtenção das curvas de desaparecimento do FDN.

Para a interpretação dos perfis de degradação da FDN dos alimentos volumosos utilizou-se o modelo assintótico exponencial decrescente de primeira ordem, conforme Mertens (1993), (Equação 1):

$\mathrm{Y}=\mathrm{Bexp}^{-\mathrm{ct}}+\mathrm{I}$

em que: $\mathrm{Y}=$ é o resíduo no tempo t; $\mathrm{B}=$ corresponde à fração potencialmente degradável; c = é a taxa de degradação; $\mathrm{t}$ = equivale aos tempos de incubação; $\mathrm{I}=$ representa a fração não-degradável.

No ajustamento do modelo ao perfil de cada unidade experimental, visando à garantia de graus de liberdade suficiente para o procedimento iterativo empregado, adotou-se a pressuposição de não-solubilização ou nãodegradação da fraçãofibrosa do alimento instantaneamente, fazendo-se, portanto, o resíduo no tempo zero idêntico à massa incubada. Empregou-se o algoritmo iterativo de Gauss-Newton modificado (SOUZA, 1998).

O efeito de repleção ruminal das frações potencialmente degradável (RR1) e não-degradável da FDN (RR2) foi estimado adaptando-se os procedimentos descritos por Waldo, Smith e Cox (1972), segundo a equação 2:
$\operatorname{RR} 1(\mathrm{~h})=\operatorname{Lim}_{\mathrm{t}} \rightarrow \infty \int_{0}^{\mathrm{t}} \mathrm{B}_{\mathrm{P}} \exp ^{-(\mathrm{c}+\mathrm{k}) \mathrm{t}} \mathrm{dt} ; \mathrm{RR} 2(\mathrm{~h})=\operatorname{Lim}_{\mathrm{t}} \rightarrow \infty{ }_{0}^{\mathrm{t}} \int_{0}$ $\mathrm{B}_{\mathrm{P}} \exp ^{\mathrm{kt}} \mathrm{dt}$; e RRt(h) = RR1+RR2

onde: $\mathrm{RRt}=$ efeito de enchimento total; $\mathrm{Bp}=$ fração decimal padronizada potencialmente degradável $[\mathrm{BP}=\mathrm{B} /(\mathrm{B}+\mathrm{I}) \times 100] ;$ Ip = fração decimal padronizada indegradável $[\mathrm{Ip}=\mathrm{I} /(\mathrm{B}+\mathrm{I}) \times 100] ; c=$ taxa de degradação de BP $\left(\% \mathrm{~h}^{-1}\right) ; t=$ tempos de incubação (horas); $k=$ taxa de passagem das partículas dos alimentos no rúmen $\left(\% \mathrm{~h}^{-1}\right)$. Para a taxa de passagem dos alimentos no rúmen $(\mathrm{k})$ adotou-se o valor de $2 \% ; 5 \%$ e $8 \%$.

\section{RESULTADOS E DISCUSSÃO}

As características químico-bromatológicas dos alimentos avaliados apresentaram variações em seus componentes nutricionais (Tabela 1). Tais variações permitem projeções representativas face ao universo de espécies, condições edafoclimáticas e demais fatores de interferência sobre a qualidade das diferentes forrageiras empregadas na alimentação de ruminantes em regiões de clima tropical.

A fração fibrosa representa um dos principais aspectos associados à avaliação de alimentos e/ou rações para os herbívoros, principalmente animais ruminantes. Logo, sua presença na dieta é primariamente ditada por sua capacidade de manutenção das relações de simbiose entre microrganismos e hospedeiro, o que está diretamente ligado à saúde e ao desempenho animal. Em muitas situações, contudo, a expressão das relações simbióticas sobre a fibra garante a sobrevivência do animal em condições de baixos recursos nutricionais e permite níveis adequados de desempenho quando a dieta é formada predominantemente por alimentos volumosos (DETMANN, 2010). O principal

Tabela 1 - Composição químico-bromatológica dos alimentos $\left(\mathrm{g} \mathrm{kg}^{-1} \mathrm{MS}\right)$

\begin{tabular}{|c|c|c|c|c|c|c|c|c|}
\hline \multirow{2}{*}{ Alimentos } & \multicolumn{8}{|c|}{ Composição químico-bromatológica } \\
\hline & MS & MO & MM & PB & FDN & FDNcp & FDA & LIG \\
\hline \multicolumn{9}{|c|}{ Fenos } \\
\hline Mata pasto & 912,9 & 875,0 & 37,9 & 60,1 & 493,0 & 456,8 & 334,8 & 72,8 \\
\hline Juazeiro & 938,7 & 886,1 & 52,6 & 89,7 & 595,5 & 555,3 & 401,8 & 172,5 \\
\hline Mororó & 921,6 & 886,2 & 35,4 & 88,2 & 562,4 & 509,5 & 437,7 & 214,6 \\
\hline Aveia & 909,2 & 856,2 & 53,0 & 69,1 & 547,1 & 528,7 & 311,3 & 60,9 \\
\hline Tifton 85 & 919,1 & 876,1 & 43,0 & 69,7 & 656,4 & 610,6 & 328,6 & 50,7 \\
\hline \multicolumn{9}{|c|}{ Silagens } \\
\hline Milho & 287,5 & 238,9 & 48,6 & 72,4 & 404,1 & 369,6 & 239,8 & 41,9 \\
\hline Sorgo & 261,9 & 218,9 & 43,0 & 52,3 & 489,9 & 370,7 & 300,2 & 61,7 \\
\hline Palma & 373,8 & 290,9 & 82,9 & 66,0 & 310,9 & 145,2 & 105,9 & 26,8 \\
\hline
\end{tabular}


atributo de relevância nutricional da FDN reside sobre a separação do alimento em duas grandes frações, as quais são completamente distintas no tocante a características de consumo e digestibilidade pelos ruminantes e outros herbívoros (MERTENS, 2003).

A porção insolúvel potencialmente degradável da FDN (Tabela 2), correspondente à fração B2, apresentou degradação variável. Observa-se que os fenos de mata pasto, juazeiro e mororó apresentaram menores valores para a fração potencialmente degradável (B). Tal fato seria esperado, uma vez que estes alimentos compõem o extrato vegetal de regiões semiáridas, atingindo maturidade fenológica precoce, determinando o aumento de estruturas de sustentação, representadas principalmente, pelos carboidratos fibrosos e pela lignina, o que, possivelmente, influenciaria o desempenho de animais alimentados com tais volumosos, o que é constatado pelos valores da fração não-degradável (I). Quando comparados aos demais volumosos avaliados, o elevado teor da fração $\mathrm{C}$ dos fenos de mata pasto, juazeiro e mororó (19,52; 48,68 e 47,49\%, respectivamente) representa também uma característica importante. A referida fração dos carboidratos totais é indisponível no rúmen e nos demais compartimentos do trato digestório dos ruminantes (FERNANDES et al., 2003), estando relacionada ao consumo voluntário de alimentos e à disponibilidade de energia dietética (DETMANN, 2010).

Quanto aos parâmetros cinéticos estimados para aFDN (Tabela 2), as silagens de milho e sorgo, apresentaram pequena variação para a fração potencialmente degradável e para a fração indigestível, assim como, para a taxa de degradação da FDN potencialmente digestível (c). Os resultados obtidos neste trabalho se aproximam dos valores encontrados por Campos et al. (2006), os quais obtiveram valores referentes às frações B e I, e à taxa de degradação da fração B, para silagem de milho, de 75,$71 ; 24,29$ e $0,027 \% \mathrm{~h}^{-1}$, respectivamente.

Considerando a degradação efetiva da FDN (DEG FDN) dos volumosos do nordeste brasileiro, o feno de juazeiro apresentou os menores valores para as taxas de passagem de 2 e $5 \% \mathrm{~h}^{-1}$, enquanto para a taxa de $8 \% \mathrm{~h}^{-1} \mathrm{o}$ menor valor foi obtido para o feno de mata pasto.

Grande parte das forrageiras arbustivas e arbóreas da caatinga apresenta elevado teor de lignina, o que provavelmente contribui para a baixa degradação da FDN. Sob ponto de vista direto, são inegáveis os efeitos da FDN sobre os valores nutritivo e alimentício das forrageiras tropicais, principalmente em função da sua elevada capacidade de repleção ruminal (LAZZARINI et al., 2009; SAMPAIO et al., 2009), a qual influencia diretamente o consumo voluntário (e, portanto, o valor alimentício), como resultado de sua insolubilidade em meios neutros, como o rúmen, e, de forma geral, em função de sua lenta utilização pelos microrganismos ruminais em comparação aos demais componentes dos alimentos (DETMANN, 2010).

Embora notoriamente a FDN de gramíneas tropicais seja mais elevada em concentraçãoe, talvez, menos degradável em comparação às forragens de clima temperado, estas características não devem ser tomadas como determinantes para o "julgamento" de fontes alimentares para bovinos nos trópicos. A alta incidência de radiação solar e maior temperatura nos trópicos são responsáveis, ao menos em parte, pela maior complexidade das interações entre carboidratos e compostos fenólicos na parede celular vegetal das gramíneas

Tabela 2 - Coeficientes de degradação (B, I e c), coeficiente de determinação $\left(\mathrm{R}^{2}\right)$ e degradabilidade efetiva da fibra em detergente neutro (DEG FDN) dos alimentos volumosos

\begin{tabular}{|c|c|c|c|c|c|c|c|}
\hline \multirow{2}{*}{ Alimentos } & \multirow{2}{*}{ B } & \multirow{2}{*}{ I } & \multirow{2}{*}{$\mathrm{c}$} & \multirow{2}{*}{$\mathrm{R}^{2}$} & \multicolumn{3}{|c|}{ DEG FDN } \\
\hline & & & & & $2 \% \mathrm{~h}^{-1}$ & $5 \% \mathrm{~h}^{-1}$ & $8 \% \mathrm{~h}^{-1}$ \\
\hline \multicolumn{8}{|c|}{ Fenos } \\
\hline Mata pasto & 31,36 & 69,68 & 0,059 & 0,85 & 23,2 & 16,8 & 13,2 \\
\hline Juazeiro & 20,16 & 79,26 & 0,164 & 0,81 & 18,1 & 15,5 & 13,6 \\
\hline Mororó & 25,99 & 71,96 & 0,104 & 0,70 & 22,3 & 17,9 & 15,0 \\
\hline Aveia & 80,01 & 18,06 & 0,045 & 0,99 & 56,5 & 38,6 & 29,4 \\
\hline Tifton85 & 84,34 & 13,48 & 0,049 & 0,99 & 61,2 & 42,7 & 32,8 \\
\hline \multicolumn{8}{|c|}{ Silagens } \\
\hline Milho & 77,09 & 22,48 & 0,022 & 0,99 & 39,8 & 23,2 & 16,4 \\
\hline Sorgo & 76,79 & 24,34 & 0,026 & 0,98 & 42,9 & 26,0 & 18,6 \\
\hline Palma & 70,09 & 29,89 & 0,026 & 0,99 & 39,6 & 24,0 & 17,2 \\
\hline
\end{tabular}


tropicais, o que, em primeira instância, constituiria fator deletério à qualidade nutricional destes alimentos para ruminantes (MALAFAIA et al., 1997).

As projeções assintóticas das frações potencialmente degradável e indegradável da FDN dos alimentos são obtidas por intermédio do ajustamento matemático das curvas de resíduos não degradados em função do tempo, obtidas em ensaios biológicos de degradação (Tabela 3). Um dos principais determinantes para o entendimento da dinâmica de degradação da FDN no ambiente ruminal reside sobre a aplicação correta de modelos matemáticos sobre o perfil dos resíduos não degradados ao longo dos tempos de incubação. Desta forma, relevam-se os principais pontos a serem observados no processo de avaliação da degradação ruminal da FDN.

As maiores RRt observadas para os alimentos avaliados ocorreram para mata pasto, juazeiro e mororó, seguidos pelas silagens, sendo constatados para os fenos de aveia e Tifton 85 os menores valores para esta variável (Tabela 3). A RRt é uma importante medida mecanicista que avalia a FDN quanto a sua disponibilidade e taxa de desaparecimento, que influencia a taxa de passagem das partículas no rúmen-retículo e, consequentemente, o consumo de nutrientes. As menores taxas de degradação para o FDN dos volumosos estudados podem ser atribuídas ao mais rápido crescimento que, embora não tenha refletido em maior concentração de lignina, deve ser lembrado que o espessamento da parede celular pode ser um fator crítico à degradação dos volumosos tropicais.

Quando comparamos os resultados obtidos para os fenos em estudo verificamos que as forrageiras do nordeste brasileiro apresentam reduzido teor da fração potencialmente degradável da FDN (Bp) e elevado teor da fração não degradável (Ip) o que acarretou em maior efeito da repleção ruminal. A fração não degradável (Ip) é um dos principais determinantes do efeito de enchimento e, por sua vez, do consumo, diminuindo à medida que se aumenta a fração potencialmente degradável. Segundo Knudsen (2001), a digestibilidade da fibra é função da fração potencialmente degradável e da taxa de digestão. Ambas as características estão relacionadas com a composição bromatológica dos alimentos. A maior RRt foi observada para o feno de juazeiro $(40,96 \mathrm{~h})$, consistindo este em forrageira arbórea com elevada concentração de lignina a qual apresenta relação inversa com o consumo.

Apesar das gramíneas tropicais, quando comparadas com as de clima temperado, acumularem ao longo de seu ciclo de crescimento elevada proporção de parede celular, o feno de Tifton 85 apresentou maior teor de fração potencialmente degradável $(\mathrm{Bp}=86,2 \%)$ que o feno de aveia $(81,6 \%)$. Tal fato ocasionou efeito de retenção total inferior ao feno de aveia, possivelmente em função do teor de lignina em relação ao teor de FDN para o feno de aveia ter sido maior $(11,13 \%)$ do que o feno de Tifton $85(7,72 \%)$.

Foi observado que entre as silagens em estudo, a de palma forrageira apresentou maior teor de fração não degradável (Ip), apesar de a mesma conter altos teores de CNF em relação às silagens de milho e de sorgo. Isto pode ser explicado pelo fato dos microrganismos que degradam os CNF apresentarem taxa de degradação superior aos que degradam a fibra. Desta forma, a maior velocidade de crescimento implica na assimilação mais rápida do substrato por microrganismos que degradam o CNF, podendo, em algumas situações, reduzir o crescimento dos microrganismos fibrolíticos por competição, mostrando que a forma e a intensidade de utilização da

Tabela 3 - Parâmetros cinéticos da degradação da fibra em detergente neutro (FDN) para os alimentos volumosos

\begin{tabular}{lcccccc}
\hline \multicolumn{1}{c}{ Alimentos } & $\mathrm{Bp}^{1}$ & $\mathrm{Ip}^{2}$ & $\mathrm{RR}^{13}$ & $\mathrm{RR}^{24}$ & $\mathrm{RRt}^{5}$ & $\mathrm{Kd}^{6}$ \\
\hline Mata pasto & 31,0 & 69,0 & 3,93 & 34,48 & 38,41 & 0,059 \\
Juazeiro & 20,3 & 79,7 & 1,10 & 39,86 & 40,96 & 0,164 \\
Mororó & 26,5 & 73,5 & 2,14 & 36,73 & 38,87 & 0,104 \\
Aveia & 81,6 & 18,4 & 12,55 & 9,21 & 21,76 & 0,045 \\
Tifton 85 & 86,2 & 13,8 & 12,50 & 6,89 & 19,39 & 0,049 \\
\hline & & Silagens & & & \\
\hline Milho & 75,9 & 24,1 & 18,07 & 12,05 & 30,12 & 0,022 \\
Sorgo & 75,9 & 24,1 & 16,51 & 12,03 & 28,54 & 0,026 \\
Palma & 70,1 & 29,9 & 15,24 & 14,95 & 30,19 & 0,026 \\
\hline
\end{tabular}

${ }^{1} \mathrm{Bp}$ - Fração potencialmente degradável $(\%) ;{ }^{2}$ Ip - Fração não-degradável (\%); ${ }^{3} \mathrm{RR} 1$ - Efeito da repleção ruminal da fração potencialmente degradável (h); ${ }^{4} \mathrm{RR} 2$ - Efeito da repleção ruminal da fração não degradável (h); ${ }^{5} \mathrm{RRt}$ - Efeito da repleção total (h); ${ }^{6} \mathrm{Kd}$ - taxa de digestão $\left(\%\right.$ h $\left.{ }^{-1}\right)$ 
FDN no ambiente ruminal são ditadas não somente pelas características do alimento (DETMANN, 2010).

Em termos nutricionais, as frações potencialmente degradáveis e indegradáveis da FDN devem ser vistas como conceitos teóricos, uma vez que todos os eventos de ação enzimática (degradação microbiana ruminal) ocorrem em escalas de tempo finitas. Assim, a forma como o substrato é trabalhado depende da ação dos sistemas enzimáticos durante o tempo no qual a interação enzima $\mathrm{x}$ substrato ocorre, ou seja, da efetividade do processo de degradação ou digestão (DETMANN, 2010). Desta forma, a efetividade do processo de degradação da FDN no ambiente ruminal é diretamente representada pela estimativa da fração efetivamente degradada da FDN, a qual associa os conceitos teóricos de potencialidade à velocidade de ação enzimática sobre o substrato e ao tempo disponível para que estes sistemas executem tais ações.

\section{CONCLUSÕES}

1. As forrageiras de regiões semiáridas avaliadas (mata pasto, juazeiro e mororó) podem limitar o consumo de matéria seca devido aos menores valores da fração potencialmente degradável e maiores valores da fração indigestível;

2.O efeito de repleção ruminal da FDN é determinado pela integração de várias características da fibra. Dessa maneira, não se pode atribuir a toda e qualquer fonte de fibra as mesmas inferências restritivas à limitação física de consumo.

\section{REFERÊNCIAS}

CABRAL, L. S. et al. Frações de carboidratos de alimentos volumosos e suas taxas de degradação estimadas pela técnica de produção de gases. Revista Brasileira de Zootecnia, v. 29, n. 06, p. 2087-2098, 2000. Suplemento 1.

CABRAL, L. S. et al. Degradabilidade in situ da matéria seca, da proteína brutae da fibra de alguns alimentos. Pesquisa Agropecuária Brasileira, v. 40, n. 08, p. 777-781, 2005.

CAMPOS, P. R. S. S. et al. Estudo comparativo da cinética de degradação ruminal de forragens tropicais em bovinos e ovinos. Arquivo Brasileiro de Medicina Veterinária e Zootecnia, v. 58, n. 06, p. 1181-1191, 2006.

CASSIDA, K. A. et al. Comparison of detergent fiber analysis methods for forages high in pectin. Animal Feed Science and Technology, v. 135, n. 03/04, p. 283-295, 2007.

DETMANN, E. et al. Validação de equações preditivas da fração indigestível da fibra em detergente neutro em gramíneas tropicais. Revista Brasileira de Zootecnia, v. 33, n. 06, p. 1866-1875, 2004.
DETMANN, E. et al. Reparametrização do modelo baseado na lei de superfície para predição da fração digestível da fibra em detergente neutro em condições brasileiras. Revista Brasileira de Zootecnia, v. 36, n. 01, p. 155-164, 2007.

DETMANN, E. Fibra na nutrição de novilhas leiteiras In: PEREIRA, E. S. et al. Novilhas leiteiras. Fortaleza: Graphiti gráfica e editora ltda, 2010. cap. 8, p. 253-332.

FERNANDES, A. M. et al. Fracionamento e cinética da degradação dos carboidratos constituintes da cana-de-açúcar com diferentes ciclos de produção em três idades de cortes. Revista Brasileira de Zootecnia, v. 32, n. 06, p. 1778-1785, 2003.

KNUDSEN, K. E. B. The nutritional significance of "dietary fiber" analysis. Animal Feed Science and Technology, v. 90, n. 01/03, p. 3-20, 2001.

LAZZARINI, I. et al. Dinâmicas de trânsito e degradação da fibra em detergente neutro em bovinos alimentados com forragem tropical de baixa qualidade e compostos nitrogenados. Arquivo Brasileiro de Medicina Veterinária e Zootecnia, v. 61, n. 03, p. 635-647, 2009.

MALAFAIA, P. A. M. et al. Determinação e cinética ruminal das frações protéicas de alguns alimentos para ruminantes. Revista Brasileira de Zootecnia, v. 26, n. 06, p. 1243-1251, 1997.

MERTENS, D. R. Rate and extent of digestion. In: FORBES, J. M., FRANCE, J. Quantitative aspects of ruminant digestion and metabolism. Cambridge: $\mathrm{CAB}$ International, Cambridge University Press, 1993. chap. 2. p. 13-51.

MERTENS, D. R. Challenges in measuring insoluble dietary fiber. Journal of Animal Science, v. 81, n. 12, p. 3233-3249, 2003.

NATIONAL RESEARCH COUNCIL. Nutrient requirements of dairy cattle. 7 th ed. Washington, D.C.: National Academy Press, 2001. 381 p.

PEREIRA, E. S. et al. Fontes nitrogenadas e uso de Sacharomyces cereviseae em dietas à base de cana-de-açúcar para novilhos: Consumo, digestibilidade, balanço nitrogenado e parâmetros ruminais. Revista Brasileira de Zootecnia, v. 30, n. 02, p. 563-572, 2001.

ROCHA JÚNIOR, V. R. et al. Determinação do Valor Energético deAlimentos para Ruminantes pelo Sistema de Equações. Revista Brasileira de Zootecnia, v. 32, n. 02, p. 473-479, 2003.

SAMPAIO, C. B. et al. Rumen dynamics of neutral detergent fiber in cattle low-quality tropical forage and supplemented with nitrogenous compounds. Revista Brasileira de Zootecnia, v. 38, n. 03, p. 560-569, 2009.

SILVA, D. J.; QUEIROZ, A. C. Análise de alimentos: (métodos químicos e biológicos). 3. ed. Viçosa, MG: Universidade Federal de Viçosa, 2002. 235 p.

SOUZA, G. S. Introdução aos modelos de regressão linear e não linear. Brasília: EMBRAPA - STI, 1998. 505 p.

VAN SOEST, P. J. Nutritional ecology of the ruminant. 2. ed. Ithaca: Cornell University Press, 1994. 476 p.

VAN SOEST, P. J.; ROBERTSON, J. B. Systems of analysis for evaluating fibrous feeds. In: PIDGEN, W. J.; BALCH, 
C. C.; GRAHAM, M. (Ed.). Standardization of analytical methodology for feeds. Ottawa: International Development Research Centre, 1980. p. 49-60.

VAN SOEST, P. J., ROBERTSON, J. B., LEWIS, B. A. Methods for dietary fiber and nonstarch polyssacarides in relation to animal nutrition. Journal of Dairy Science, v. 74, n. 10, p. 3583-3597, 1991.
VIEIRA, R. A. M. et al. Simulação da dinâmica de nutrientes no trato gastrintestinal: aplicação e validação de um modelo matemático para bovinos a pasto. Revista Brasileira de Zootecnia, v. 29, n. 03, p. 898-909, 2000.

WALDO, D. R.; SMITH, L. W.; COX, E. L. Model f cellulose disappearance from the rumen. Journal of Dairy Science, v. 55, n. 01, p. 125-129, 1972. 